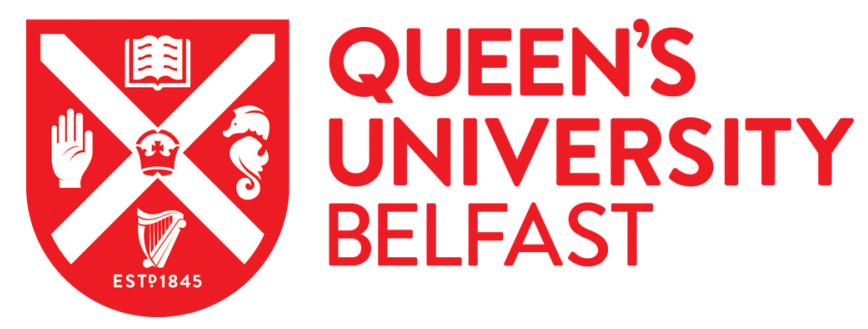

\title{
The EIT Food School Network: Integrating solutions to improve eating habits and reduce food wastage in secondary schoolchildren
}

\author{
Capper, T., Woodside, J., Brennan, S., \& McKinley, M. (2019). The EIT Food School Network: Integrating \\ solutions to improve eating habits and reduce food wastage in secondary schoolchildren. Nutrition Bulletin. \\ https://doi.org/10.1111/nbu.12406
}

Published in:

Nutrition Bulletin

Document Version:

Peer reviewed version

Queen's University Belfast - Research Portal:

Link to publication record in Queen's University Belfast Research Portal

Publisher rights

(C) 2019 British Nutrition Foundation.

This work is made available online in accordance with the publisher's policies. Please refer to any applicable terms of use of the publisher.

\section{General rights}

Copyright for the publications made accessible via the Queen's University Belfast Research Portal is retained by the author(s) and / or other copyright owners and it is a condition of accessing these publications that users recognise and abide by the legal requirements associated with these rights.

Take down policy

The Research Portal is Queen's institutional repository that provides access to Queen's research output. Every effort has been made to ensure that content in the Research Portal does not infringe any person's rights, or applicable UK laws. If you discover content in the Research Portal that you believe breaches copyright or violates any law, please contact openaccess@qub.ac.uk. 


\section{The EIT Food School Network: Integrating solutions to improve eating habits and reduce food wastage in secondary school children}

T Capper; S Brennan; J Woodside; M McKinley

Queen's University Belfast Ringgold, Centre for Public Health Belfast, United Kingdom of Great Britain and Northern Ireland

Corresponding Author:

Dr Tess Capper, Research Fellow, Queen's University Belfast - Centre for Public Health, Institute of Clinical Sciences Block B Queen's University Belfast Grosvenor Road Belfast BT12 6BJ, United Kingdom of Great Britain and Northern Ireland. Email: T.Capper@qub.ac.uk

Abstract: Most European children and adolescents do not meet dietary guidelines. Therefore, there is a need to develop and implement effective strategies to help young people adopt healthier dietary habits and maintain these into adulthood. The amount of time that children and adolescents spend in the school setting makes this an ideal environment in which to develop interventions that target healthy eating. Schools, however, are complex systems and a whole school approach that promotes consistent messages within the school environment and across the curriculum is needed to support positive food choices. Given current concerns about climate change and the environment, it is also important to ensure that any nutrition interventions implemented in the school setting are environmentally friendly and do not increase food wastage. This paper presents the results of stakeholder discussions on the topic of secondary school food in Northern Ireland, conducted as part of the recently developed EIT Food School Network. The Network was established to facilitate the exchange of information within existing national schools programmes and to identify and develop strategies that positively impact on food choice and food wastage in schools across Europe. Improving schools' adherence to the Food in Schools Policy and engaging pupils and parents to encourage a sense of 'ownership' of the school food system were identified as potential ways to positively impact on the dietary habits of children and adolescents.

Keywords: school-aged children, school food, nutrition, food choice, adolescents 


\section{Introduction}

There is an increasing recognition of the role and importance of schools in the health and healthrelated behaviours of children and adolescents (Robinson 2014; Van Cauwenberghe 2010; Vezina-Im 2017). Young people spend around 25 hours per week at school (Godin et al. 2015) and, for the first two decades of life, no other institution has as much intensive, direct and continuous contact with children and adolescents (Roseman et al. 2011). Schools provide a platform upon which positive behaviour change techniques can be implemented and evaluated, and offer the opportunity to reach young people regardless of their age, ethnicity and socioeconomic status (Vezina-Im 2017). Schools can be an ideal environment in which to promote healthful dietary choices through food provision, food and nutrition education, and healthy school policies. However, it has also been argued that the school setting can play a role in the development and maintenance of overweight and obesity through the promotion of high-energy food intake and sedentary behaviour (Ermetici et al. 2016; Townshend and Lake 2017; Swinburn et al. 2011). Modifying the school environment, particularly targeting health promotion and dietary change, has the potential to support the development of healthy lifestyle habits that can be carried into adulthood (Calvert et al. 2019).

A healthy diet during childhood and into adolescence supports growth and cognitive development, and may contribute to good health and the prevention of a number of chronic diseases in later life (Centres for Disease Control and Prevention 1997; Lytle \& Kubik 2003; Willett 1994). Habits developed through childhood and adolescence tend to be preserved into adulthood (Van Cauwenberghe et al. 2009); however, the transition from childhood to adolescence is associated with an increased likelihood of consuming an unbalanced diet. A young person's understanding of what constitutes healthy eating is not necessarily the same as an adult's, often due to a lack of knowledge and limited experience, and good understanding does not necessarily translate to healthful dietary choices. A young person's food preferences are partly driven by innate preference for sweet and salty tastes, as well as energy dense foods (Birch 1999; Cooke \& Wardle 2005). Fussiness about unfamiliar or unappealing foods and a lack of desire to eat less energy dense foods such as vegetables can result in food wastage (WRAP 2011). Adolescents experience an increase in autonomy in all aspects of their life, including food and drink choices, and so are important targets for behaviour change within school settings. Research suggests that young people consume between one third and one half of their daily energy intake whilst in schools (Micha et al. 2018; Nathan et al. 2019), underscoring the importance of healthy school environments in the promotion of positive eating behaviours.

Schools can both promote and create barriers to healthy dietary behaviours and the whole school food environment, from the canteen to provisions at break time, can work to reinforce or impede positive messages delivered through the curriculum (Shilton \& Corti 1992). Authorities within schools have the potential to make a significant impact on the health of their pupils through the curriculum chosen, policies adopted, and the physical and social environment provided (Carter \& Swinburn 2004). The Centres for Disease Control (1997) describe successful school food programmes as those that target multiple components including the curriculum, food service, school policy and parents.

Interventions to improve the diets of school children have been associated with food wastage in the US (Byker et al. 2014; Smith and Cunningham-Sabo, 2014) and case studies have reported food wastage issues in European schools (Falasconi et al. 2015; WRAP 2011). Food waste can be defined as discarded products that still preserve their nutritional value and comply with safety standards (Falasconi et al. 2015). The Waste and Resources Action Programme (WRAP) describe three major issues with food waste in schools: 1) energy from the growth, transportation, storage and 
preparation of the foods is also wasted; 2) money spent on buying and preparing the food is wasted; and 3) children do not gain the nutritional benefits of the wasted food. It is estimated that up to 24 974 tonnes of food waste is generated in secondary schools each school year in England alone (WRAP 2011). Previous research has found vegetables to be one of the most wasted foods in the school canteen (Byker et al. 2014; WRAP 2011). A number of factors contributing to food waste, specifically in the secondary school environment, have been identified by WRAP (2011). These include the absence of pre-ordering systems leading to kitchens catering for unknown numbers of pupils, inflexible portion sizes, fixed food combinations, rushed mealtimes, and pupils buying cheaper snacks rather than a full meal. Thus, reducing food waste, as well as educating pupils on the issue of food waste, should be a consideration in the development of school food policies (Derqui et al. 2018).

The primary goal of the recently developed EIT Food School Network is to positively influence the dietary habits of children and adolescents and their perceptions of healthy eating, as well as reduce food waste in schools. Results will be gathered from effective healthy eating interventions conducted in pre-, primary and secondary schools and translated for use by key stakeholders across the multiple sites in the network, including the UK, Spain, Finland and Poland. New interventions are also being developed by the School Network, which will be tailored according to pupil age (preschool through to secondary school) and the prevailing school food systems in the different countries included in the network. These new approaches involve exploring nutritional understanding and perception of school meals, examining food choice and the concept of healthy food in young people, and investigating children's health behaviours and stress response regulation.

This paper presents the outcome of a series of discussions, organised by the EIT Food School Network, with key stakeholders of school food provision in Northern Ireland . The aim was to better understand the secondary school food systems in this region and identify potential priority areas for intervention. The findings may help in the development of effective strategies to improve dietary habits in children and adolescents that can be applied by the EIT Food School Network and beyond.

\section{Overview of diet and eating behaviours of secondary school-aged children}

According to the latest UK National Diet and Nutrition Survey (NDNS), children and young people aged 11-18 years have lower than recommended intakes of dietary fibre, vitamin A and folate (PHE 2018). This age group also has the highest intake of free sugars, contributing to $13.9 \%$ and $14.4 \%$ of total daily energy intake in boys and girls respectively (PHE 2018). Non-alcoholic beverages provide $33 \%$ of total free sugars intake in those aged $11-18$ years, followed by $29 \%$ from 'cereal and cereal products' and $21 \%$ from 'sugar, preserves and confectionery'. Additionally, only $8 \%$ this age group achieve the 5 A DAY recommendation for fruit and vegetable intake, consuming on average 2.7 portions per day (PHE 2018). The over-consumption of energy-dense, nutrient-poor foods and drinks, such as sugars-sweetened beverages and confectionery, and low intakes of fruit and vegetables puts this age group at significantly higher risk of unhealthy weight gain and the development of chronic disease in the future (Nathan et al. 2019). Overall, research suggests that most European children and adolescents do not meet dietary guidelines (PHE 2018; Ruxton \& Derbyshire 2011) and this likely contributes to the prevalence of overweight and obesity in these age groups (Swinburn et al. 2011). The onset of obesity in adolescence is associated with increased risk of obesity in later life and the development of obesity-related conditions (Dietz 1994).

Early research has suggested that healthy eating messages may be reaching adolescents but there is a lack of translation of this knowledge into healthier behaviours (Croll et al. 2001; Stevenson et al. 2007). Barriers to healthy eating in this age group at school include competing priorities around 
healthy eating such as the desire to 'fit in' socially, as well as the sometimes limited availability of healthy foods in school (Croll et al. 2001; Stevenson et al. 2007). Neuroendocrine changes and increased autonomy in relation to food that occur during adolescence may have an impact on attitudes and behaviours related to healthy eating. Adolescents also exert a particularly powerful social influence on the behaviour of their peers (Yip et al. 2016; Brown 2004; Dumontheil et al. 2016), with positive attitudes and behaviours in relation to healthy eating having a positive influence on others' food choices (Larson et al. 2009).

\section{Key differences between primary and secondary school healthy eating interventions}

To date, research into health and wellbeing policies in schools has largely neglected secondary school aged pupils, and more research is needed to provide insight into ways to engage young people with healthy eating during this key developmental stage that significantly influences the development of health behaviours that persist into adult life (Kleinert \& Horton 2016). There is also a shortage of research on the social aspect of school meal consumption involving factors such as peer influence (Lalli 2019). School meals form part of the school culture and represent more than just food provision (Kwon et al. 2018). Thus, social and cultural aspects of school meals should be considered in the development of healthy eating interventions and school policies to improve health and diet in secondary schools in particular.

Systematic reviews of school-based nutrition interventions highlight the disparity in the number of studies in secondary schools compared to pre-school and primary school (e.g. Van Cauwenberghe et al. 2010). Van Cauwenberghe et al. (2010) describe more than double the number of studies in younger children (classified as younger than 12 years) compared to older children and adolescents, in addition to a higher quality of studies in the younger age group. Pre-school and primary school settings in Northern Ireland, as well as other regions across Europe, favour set menus and dishes, therefore limiting food choice. In secondary schools, however, there tends to be greater variety of foods and meals offered and canteens may include self-service counters and single-priced items. Furthermore, external food outlets, vending machines and tuck shops provide older children with increased food choice and greater autonomy in their eating patterns during the school day. Secondary school-based interventions to improve health eating may, therefore, require a multifaceted approach that targets not only school canteens but also other food outlets accessed by students.

The evaluation and analysis of healthy eating interventions can be more challenging in secondary than primary school settings due to the increased variety of food available to secondary school pupils. With a lower uptake of school meals due to the availability of other food options in secondary schools, the provision of healthy school meals alone may not be enough to improve the food choices and diets of adolescents. In addition, parents tend to have less control over the eating habits of their children as they move from primary to secondary school and become more independent. Parental and peer influence on children's and young people's food choices, and healthy eating motivations and barriers, must all be considered to create a cohesive and effective approach to improving the diet of secondary school-aged children.

\section{Research within the EIT Food School Network - stakeholder discussions in Northern Ireland}

In Northern Ireland, the Education Authority (EA) governs the majority of schools and is responsible for their school meals. A smaller number of other schools, such as Voluntary Grammars, are run by a Board of Governors, which is also in charge of the food in these schools. Nutritional standards for school lunches in Northern Ireland were introduced in September 2007 and extended in August 
2008 to cover all school food including from vending machines and tuck shops. Nutritional standards for school meals apply to all secondary level schools in Northern Ireland; however, schools not governed by the EA vary in their application of the standards. In 2013, the Food in Schools Policy was published by the Department of Education (DE) and the Department of Health, Social Services and Public Safety (DH) and rolled out to EA-governed schools. The policy advocates a 'whole-school approach' and aims to promote healthy eating in school as well as support dietary change outside of school. In addition to $\mathrm{DE}$ and $\mathrm{DH}$, several other stakeholders are involved in the implementation and evaluation of the Food in Schools Policy through participation in the Regional Food in School Forum, which was established in 2009. These include the regional Food in Schools Coordinator and representatives from the Public Health Agency (PHA), SafeFood, the Food Standards Agency, EA, and Council for the Curriculum, Examinations and Assessment (CCEA).

In order to improve understanding of the current secondary school food system in Northern Ireland and to identify potential priority areas for intervention, we conducted semi-structured interviews and small discussion groups with representatives $(n=15)$ from the above organisations to explore topics such as adherence to the nutritional standards, the implementation of the new Food in Schools Policy, and food waste in the canteen environment before and after the implementation of the policy. This study received ethical approval from the School of Medicine, Dentistry and Biomedical Sciences Ethical Committee, Queen's University Belfast and participants provided informed consent prior to undertaking this research. The interviews and discussion groups were conducted between November and December 2018, as part of the EIT Food School Network.

\section{Results of stakeholder discussions on secondary school food}

Stakeholders described the current nutritional standards in Northern Ireland as relevant, extensive and covering not only canteen meals but also the wider food environment (e.g. vending machines and lunch boxes). While adherence to the nutritional standards varies between schools, overall its implementation was thought to have significantly improved the provision of healthier food choices in schools in Northern Ireland. However, stakeholders stated that re-structuring and the current lack of monitoring of nutritional standards in schools have had a negative impact on adherence, with wide variations in how schools understand or interpret 'healthy options'. Stakeholders agreed that one significant challenge to the success of the Food in Schools Policy in secondary schools is when pupils are given permission to leave the school grounds at lunchtime and thus purchase food offsite. Where this is permitted, there tends to be lower uptake of school meals and a lack of data on the nutritional value of meals purchased outside school.

While implementation of the Food in Schools Policy occurs only in schools governed by the EA, stakeholders highlighted that all schools in Northern Ireland are entitled to advice and support from the EA School Catering Service. Schools such as Voluntary Grammar schools have different budgets and procurement systems in place for school meals and stakeholders agreed that schools such as these do not typically utilise the EA support offered. Stakeholders described that income generation from canteens and vending machines may play a more influential role in these particular schools. It was discussed that instead of additional healthy eating policies and initiatives for schools not governed by the EA, it may be more effective for all secondary schools to adhere to the Food in Schools Policy, regardless of their governance structure. Online dietary resources are available for schools in Northern Ireland, which are designed to support implementation of the Food in Schools Policy. However, stakeholders felt that these resources were targeted mostly at primary school age children in Northern Ireland, and so there may be an opportunity to develop more resources specifically for secondary schools or to signpost to existing resources for this age group. A number of 
stakeholders suggested that social media presence might raise awareness of the Food in Schools Policy and the support that is available to aid its implementation.

Throughout discussions, all stakeholders highlighted the complexity of the secondary school food environment compared to the primary school setting, which tends to offer fewer meal choices at lunch time and is more likely to implement break time snack policies. Giving pupils more of a sense of ownership of the school food environment and involving pupils and parents in its management may help to improve pupils' dietary behaviours. It was highlighted that an emerging priority within the school food environment is the need to cater for allergy sufferers. Allergen-free meal provision and awareness of cross-contamination must be considered alongside the provision of nutritionally balanced menus and adherence to the nutritional standards, which adds to the complexity of the system and increases workload. A number of stakeholders highlighted the importance of striking a balance between achieving dietary and health objectives, catering for special diets, and making sure the meals are palatable and appealing to the pupils who are the paying customers. The importance of taking into account a whole-school perspective on these matters was highlighted, as opposed to solely focusing on health considerations.

The stakeholders did not consider food waste as a major issue currently within secondary schools in Northern Ireland. Stakeholders explained how, in schools governed by the EA, catering teams have strict procurement guidelines and budgets, and therefore that food waste in the kitchen is tightly controlled. However, stakeholders described that currently there are no systems in place to monitor food wasted by the pupils but that catering staff, based on experience, are able to tailor kitchen outputs to pupil preference (i.e. less popular items are served infrequently, if at all, to minimise food wastage). Such actions to limit food wastage may limit pupils' exposure to certain foods, particularly vegetables and oily fish, and alter the nutritional composition of meals served at lunchtime. Stakeholders also discussed how the provision of special diets (i.e. catering to food allergies and intolerances, religious beliefs and personal preference), as discussed above, can impact significantly on school canteen management, workload and waste.

The stakeholders highlighted that a lack of monitoring of food wastage since the introduction of the Food in Schools Policy may mean inaccurate assumptions are being made about the impact of this policy on school canteen waste. It was also emphasised that while strict budgeting and procurement systems may prevent over purchasing and/or excess production of meals, pupil preference and attitudes towards healthier meal options introduced to satisfy the nutritional standards are likely to be contributors to food waste. Future interventions aimed at improving the dietary habits of secondary school pupils should assess the effect on food waste in addition to dietary behaviours. Research into pupil preferences, diet-related motivations and barriers to healthy eating will help to inform the development of successful interventions.

Overall, the major themes that emerged from the stakeholder discussions about secondary school food in Northern Ireland were that: 1 ) variable adherence and a lack of monitoring of the nutritional standards and the Food in Schools Policy exists; 2 ) resources to support implementation of the Food in Schools Policy in secondary schools are lacking; and 3) the secondary school environment, including varying governance, off site purchasing and special diet provision, is complex. These themes might help to explain some of the difficulty in developing effective nutritional interventions in secondary schools and also to identify areas in which positive changes can be made.

\section{Current and future research aims}


There is evidence to suggest that, before the nutritional standards for schools came into effect, pupils were dissatisfied with many aspects of the school food environment such as food quality and appeal (Kubik et al. 2003; Neumark-Sztainer et al. 2005), but there has been limited research on this topic since the introduction of nutritional standards. Stakeholder discussions highlighted the need to involve secondary level pupils and parents in decisions about the school food environment at all stages to ensure that their views are considered in the development of healthy eating policies and related services. However, engaging parents and pupils in such activities might be challenging due to the significant time commitment involved. Future work of the EIT Food School Network will investigate the eating behaviours, facilitators and barriers to healthy eating, and attitudes towards food waste of secondary school pupils in Northern Ireland to understand how to better engage with this group on the topic of healthy eating.

Previous research has shown that, within the UK, the levels of school food standard adherence and evaluation are highly variable (Adamson et al. 2013), and the stakeholders discussions indicated that this might also be the case in Northern Ireland. Reinstating regular monitoring of adherence to nutritional standards and the Food in Schools Policy may be required to encourage schools to focus resources in this area and to identify where additional support is required.

\section{Conclusion}

The secondary school food environment is a complex system in which factors such as pupil independence, peer influence, and increased freedom in food choice, which are less relevant to preand primary school settings, play an important role in the pupils' engagement with healthy eating policies. In the present research, stakeholders highlighted a number of key areas of the secondary school food environment in Northern Ireland that might be targeted in an effort to positively influence dietary habits in children and adolescents. These include improved adherence to the Food in Schools Policy and engagement in this policy by pupils and parents to encourage a sense of ownership of the school food system. Future research within the EIT Food School Network will explore the school food environment in Northern Ireland from the perspective of pupils, parents and school management to identify strategies to engage these key stakeholders in healthy school policies.

\section{Acknowledgments}

This work was funded by the EIT Food Horizon 2020 funding. The funder had no role in the conduct of the research, in the decision to publish or in reviewing or approving the manuscript.

\section{Conflict of interest}

The authors have no conflict of interest to declare.

\section{References}

Adamson A, Spence S, Reed L et al (2013) School food standards in the UK: implementation and evaluation. Public Health Nutr, 16: 968-81.

Birch LL (1999) Development of food preferences. Annu Rev Nutr, 19: 41-62.

Brown BB (2004) Adolescents' relationships with peers. In: Handbook of Adolescent Psychology (eds L Steinberg \& RM Lerner, 2nd edn, pp 363-389. John Wiley \& Sons, Inc: New Jersey

Buzby JC, Guthrie JF (2002) Plate waste in school nutrition programs: final report to congress. Economic Research Service, U.S. Department of Agriculture, Washington DC. 
Byker CJ, Farris AR, Marcenelle $M$ et al (2014) Food waste in a school nutrition program after implementation of new lunch program guidelines. Journal of Nutrition Education and Behaviour, 46: 5.

Calvert S, Dempsey RC, Povey R (2019) Delivering in-school interventions to improve dietary behaviours amongst 11- to 16-year-olds: a systematic review. Obes Rev, 20: 543-553.

Carter MA, Swinburn B (2004) Measuring the 'obesogenic' food environment in New Zealand primary schools. Health Promot Int, 19: 15-20.

Centres for Disease Control and Prevention (1997) Guidelines for school health programs to promote lifelong healthy eating. J Sch Health, 67: 9-26.

Cooke L, Wardle J (2005) Age and gender differences in children's food preferences. British Journal of Nutrition, 93: 741-746.

Croll JK, Neumark-Sztainer D, Story M (2001) Healthy eating: what does it mean to adolescents? Journal of Nutrition Education, 33: 193-198.

Derqui B, Fernandez V, Fayos T (2018) Towards more sustainable food systems. Addressing food waste at school canteens. Appetite, 129: 1-11.

Dietz WH (1994) Critical periods in childhood for the development of obesity. The American Journal of Clinical Nutrition, 59: 955-959.

Dumontheil L, Wolf LK, Blakemore S (2016) Audience effects on the neural correlates of relational reasoning in adolescence. Neuropsychologia, 87: 85-95.

Ermetici F, Zelaschi RF, Briganti S et al (2016) Association between a school-based intervention and adiposity outcomes in adolescents: the Italian "EAT" project. Obesity, 24: 687-95.

Falasconi L, Vittuari M, Politano A et al (2015) Food waste in school catering: an Italian case study. Sustainability, 7: 14745-14760.

Godin K, Leatherdale ST, Elton-Marshall T (2015) A systematic review of the effectiveness of schoolbased obesity prevention programmes for First Nations, Inuit and Metis youth in Canada. Clinical Obesity, 5: 103-15.

Gordon K, Dynan L, Siegel R (2018) Healthier choices in school cafeterias: a systematic review of cafeteria interventions. J Pediatr, 203: 273-9.

Kleinert, S, Horton R (2016) Adolescent health and wellbeing: a key to a sustainable future. Lancet, 387: 2355-6.

Kubik MY, Lytle LA, Hannan PJ et al (2003) The association of the school food environment with dietary behaviors of young adolescents. Am J Public Health, 93: 1168-1173.

Kwon S, Kim O, Lee Y (2018) Effects of students' satisfaction with school meal programs on school happiness in South Korea. Nutrition Research and Practice, 12: 342-347.

Lalli GS (2019) School meal time and social learning in England. Cambridge Journal of Education. DOI: $\underline{10.1080 / 0305764 X .2019 .1630367}$

Larson NI, Neumark-Sztainer D, Harnack $\amalg$ et al (2009) Fruit and vegetable intake correlates during the transition to young adulthood. American Journal of Preventative Medicine, 35: 33-37. 
Lytle LA, Kubik MY (2003) Nutritional issues for adolescents. Best Pract Res Clin Endocrinol Metab, 17: 177-189.

Micha R, Karageorgou D, Bakogianni I et al (2018) Effectiveness of school food environment policies on children's dietary behaviors: a systematic review and meta-analysis. PLoS One, 13: e0194555.

Nathan N, Janssen L, Sutherland R et al (2019) The effectiveness of lunchbox interventions on improving the foods and beverages packed and consumed by children at centre-based care or school: a systematic review. Int J Behav Nutr Phys Act, 16.

Neumark-Sztainer D, French SA, Hannan PJ et al (2005) School lunch and snacking patterns among high school students: associations with school food environment and policies. IJBNPA, 2: 14

Public Health England. (2018). National Diet and Nutrition Survey, results from Years 7 and 8 (combined) of the rolling programme (2014/2015 to 2015/2016). Available at: https://www.gov.uk/government/statistics/ndns-results-from-years-7-and-8-combined (accessed $16^{\text {th }}$ July 2019).

Robinson LE, Webster EK, Whitt-Glover MC et al (2014) Effectiveness of pre-school- and schoolbased interventions to impact weight-related behaviours in African American children and youth: a literature review. Obesity Reviews, 15: 5-25.

Roseman MG, Riddel MC, Haynes JN (2011) A content analysis of kindergarten-12 ${ }^{\text {th }}$ grade schoolbased nutrition interventions: taking advantage of past learning. J Nutr Educ Behav, 43: 2-18.

Ruxton CHS, Derbyshire E (2011) Diet adequacy in UK schoolchildren. Nutrition and Food Science, 41: 20-33.

Shilton T, Cortie B (1992) School heart health promotion. National Heart Foundation of Australia's activities. Hygie, 11: 11-16.

Smith SL \& Cunningham-Sabo L (2014) Food choice, plate waste and nutrient intake of elementaryand middle-school students participating in the US National School Lunch Program. Public Health Nutrition, 17: 1255-1263.

Stevenson C, Doherty G, Barnett J et al (2007). Adolescents' views of food and eating: identifying barriers to healthy eating. Journal of Adolescence, 30: 417-434.

Swinburn BA, Sacks G, Hall KD et al (2011) The global obesity pandemic: shaped by global drivers and local environments. Lancet, 378: 804-14.

Townshend T, Lake A (2017) Obesogenic environments: current evidence of the built and food environments. Perspect Public Health, 137: 38-44.

Van Cauwenberghe E, Mae L, Spittaels $\mathrm{H}$ et al (2010) Effectiveness of school-based interventions in Europe to promote healthy nutrition in children and adolescents: systematic review of published and 'grey' literature. Br J Nutr, 103: 781-797.

Vezina-Im LA, Beaulieu D, Belanger-Gravel A et al (2017) Efficacy of school-based interventions aimed at decreasing sugar-sweetened beverage consumption among adolescents: a systematic review. Public Health Nutr, 20: 2416-2431.

Willett WC (1994) Diet and health: what should we eat? Science, 264: 532-537. 
Wills W, Backett-Milburn K, Gregory S et al (2005) The influence of the secondary school setting on the food practices of young teenagers from disadvantaged backgrounds in Scotland. Health Education Research, 20: 458-465.

WRAP (2011) Food waste in schools. Summary report. Available at:

www.wrap.org.uk/sites/files/wrap/Food\%20Waste\%20in\%20Schools\%20Summary\%20Report.pdf

Yip C, Gates M, Gates A et al (2016) Peer-led nutrition education programs for school-aged youth: a systematic review of the literature. Health Educ Res, 31: 82-97. 